\title{
Students learning in clinical practice, supervised in pairs of students - a phenomenological study
}

\author{
Hanna Holst, Ulrica Hörberg \\ School of Health and Caring Sciences, Lifeworld Centre for Health Care and Learning, Linnaeus University, Sweden
}

Correspondence: Hanna Holst. Address: George Lückligs väg 8, 35195 Växjö, Sweden. Telephone: 0046-707-347-677. Email: hanna.holst@Inu.se.

Received: August 30, 2012

Accepted: October 23, 2012

Online Published: January 31, 2013

DOI : $10.5430 /$ jnep.v3n8p113

URL: http://dx.doi.org/10.5430/jnep.v3n8p113

\section{Abstract}

Background: Clinical studies have an important position in Nursing Education, it is thus important to develop the learning strategies of students in order to facilitate their learning process during the clinical practice. The aim of the study is to describe the process of students' learning towards their profession, when supported by supervision in pairs.

Methods: Data has been collected through interviews of students during their clinical studies. The study has been carried out with a Reflective Lifeworld Research (RLR) approach founded on phenomenological traditions. The clinical settings are based on the model of the Developing and Learning Care Unit that has a structure that supports students in their learning towards becoming nurses.

Results: Results show that structured supervision is favourable for students learning, where pair of students, space and time play a significant role. The results are illustrated in following themes: The significance of responsibility for learning, the strength and sensitivity in pairs of students, the focus on doing, the significance of the attitude of the supervisor, the vulnerability and potential of the learning environment and Reflection as a possibility and a pre-requisite.

Conclusions: The study shows that the conduct of supervising in pair of students is of great importance for students' learning and it is thus important to develop a reflective supervising approach and also knowledge of how to support students' learning.

\section{Key words}

Caring science, Learning, Lifeworld, Nursing students, Phenomenology, Reflection

\section{I ntroduction}

Clinical studies have an important position in Nursing Education, it is thus important to develop the learning strategies of students in order to facilitate their learning process during the clinical practice. The present study will focus on students' lived experiences of their learning in their progression towards being nurses, when supervised in pairs.

Benner, Sutphen, Leonard and Day ${ }^{[1]}$ illustrate the importance of students being active in caring for patients as soon as possible during the training rather than observing qualified nurses as a shadow. They also suggest making the expert performance of nurses visible to nursing students in order to: facilitate supervision in the learning process, enable students to reflect on their practice, help students to prioritize and help students develop a self-improving practice through 
reflection. Ekebergh ${ }^{[2]}$ maintains that it is very important with structured learning in order to enable students to integrate caring science when encountering patients. Students need to intertwine their theoretical knowledge with their practical knowledge and at the same time include the patient's lifeworld in their learning process ${ }^{[2,3]}$. The same author ${ }^{[2,3]}$ discusses the students' learning process and their understanding in the encounter with patients and also states that students require support in analyzing patient situations in order for them to see all the parts in relation to the whole. Students require support from a supervisor in order to facilitate this process, which is very important for the learning but also for the creation of a good learning environment with a foundation in the student's lifeworld ${ }^{[2-5]}$.

Earlier studies show that a significant part of nursing students' clinical studies consists of being able to feel secure and welcome ${ }^{[6-8]}$. It has also been found that student nurses can bridge the gap between theory and practice through reflection ${ }^{[9]}$ and through the integration of theoretical learning in practice ${ }^{[10]}$. Healthcare professionals who include students in their work and who have a good ability to communicate and integrate both theory and praxis and who share their knowledge are important for the development of nursing students towards their future profession. On the other hand healthcare professionals, who do not show interest in the students' learning process, reduce the latter's motivation for learning ${ }^{[3,7,11-15]}$. Being introduced to a well-organized clinical practice is important for the students' ability to learn ${ }^{[6,10]}$. Most students feel anxiety at the beginning of their clinical studies, which can be reduced as they gain experience ${ }^{[8]}$. Successful supervisors had a positive impact on students' learning and development towards their future profession and self-esteem ${ }^{[7,8]}$. Reflection that expands and deepens the nursing students' understanding is described as important for their learning process ${ }^{[14,16,17]}$ and their development of new thinking ${ }^{[10]}$. Holst and Hörberg ${ }^{[18]}$ showed that students created a comprehensive understanding through encountering the otherness in patients; they also made efforts to understand the patients from a lifeworld perspective through reflection.

The review of the literature above indicates the importance of gaining knowledge about the learning situation of student nurses and how to facilitate their development via structured supervision. Little is, however, known about students' experiences of their learning process towards their professional role when receiving supervision in pairs and how the didactics that are founded on caring science theories can enable reflection and shared learning. The aim of the study was thus to describe the learning process of student nurses towards their professional role when supported by supervision in pairs.

\section{Methods}

\subsection{Design}

The present study has been carried out with a Reflective Lifeworld Research (RLR) approach founded on phenomenological traditions ${ }^{[19]}$. The RLR approach is based on the continental philosophy of Husserl through his lifeworld theory ${ }^{[20]}$ and theory of intentionality ${ }^{[21]}$ and Merleau-Ponty's ${ }^{[22,23]}$ further development of these theories. Husserl ${ }^{[20]}$ describes the lifeworld as our natural being to the world with a natural attitude, i.e. unreflective attitude. He also describes our consciousness as always being directed outwards, towards something other than ourselves. It is first when we become aware of that and how we perceive something and emerges from the natural attitude that we can have a distance from what we experience and can create another understanding of the phenomenon ${ }^{[21]}$. Merleau-Ponty ${ }^{\text {[22] }}$ has further clarified a man's existence as being in the world as a lived body where there are no dividing lines between body and soul, and the theory "The flesh of the world" ${ }^{[23]}$ with the meaning that everything, both men and matter are from the same "flesh" in the same world, i.e. the body, soul and world cannot be separated. The phenomenological epistemology has to be understood in a scientific approach when applying RLR. Dahlberg et al. ${ }^{[19]}$ maintains, based on Husserl and Merleau-Ponty, that with our natural attitude we always perceive things in the world as being something. Moreover when analyzing from a RLR approach, the reflective attitude is to not understand too quickly and to not define what is undefined but also to be careful in ascribing something to the phenomenon that does not belong to that phenomenon ${ }^{[19,24]}$ i.e. an openness and flexibility is needed towards the phenomenon that is studied. This reflective attitude is described as 
"bridling” and has been developed from Husserl’s ${ }^{[21]}$ concept of "bracketing”. Bridling should be understood as not letting our pre-understanding prevail in an unreflected manner in our understanding of the phenomenon ${ }^{[19]}$. Bridling covers the understanding as a whole, even the pre-understanding, bridling is to wait for the phenomenon and to allow it to present itself $^{[19,25]}$. In order to adopt the RLR approach, an open attitude was kept to the phenomenon and at the same time bridling the understanding of the phenomenon, in this case, student's learning towards becoming professional nurses, when supervised in pairs.

\subsection{Clinical settings}

The clinical settings are based on the model of the Developing and Learning Care Unit ${ }^{[2-4,16,26]}$ with a structure designed from a lifeworld perspective to integrate theory and practice through reflection, this to support students in their learning process towards becoming nurses. Within the Developing and Learning Care Unit a pair of students are supervised by a supervision team that consists of one nurse (base supervisor), supervising students in the bedside area, one nurse (head supervisor with a practical caring science perspective) and one teacher (a lecturer from the nursing education with a theoretical caring science perspective) both responsible for assessing students nursing skills and supervising groups of students with the aim of integrating theory and practice ${ }^{[26]}$. Pairs of students consisting of one from the 4 th term and one from the 6th term, (the nursing programme consists of 6 terms and a total of 3 years of study) who are working in pairs during their five week of clinical practice. The more senior student in 6th term is responsible for the role of supervising the student in 4th term. Students are randomly sorted into pairs by the teacher before the first day of clinical practice and are introduced to each other and the ward on their first day of clinical practice by their head supervisor and teacher.

\subsection{Participants}

Twelve female nursing students, aged between 21 and 34 years, were interviewed in pairs in the last week of their five week clinical practice at a general hospital. The students that were included in the study had varying experience as caregivers, from two months to six years, and three of them had been trained as assistant nurses. A total of six pairs from four clinical units (from the medicine, surgery and infection specialities) at two hospitals were included in the study.

\subsection{Data collection}

Data was collected by the second author in the form of interviews of twelve nursing students in their six pairs, i.e. six interviews. These took place at the clinical setting in a separated room. The interviews lasted for approximately one hour and were recorded and transcribed verbatim. Open questions were asked in order to capture the experience of students' learning in their clinical practice, when supervised in pairs. The interviews started with the opening question: "Would you like to describe your experience from working and being supervised in pairs?” Further open-ended questions were asked in order to gain a deeper understanding of the students' lived experiences of the phenomenon, for example "Can you give me an example?”, “Could you tell me more about...?” and "What did you learn from that situation?” The interviewer retained a reflective attitude throughout the interviews and tried to create a reflective environment in order to access the phenomenon.

\subsection{Data analysis}

The data has been analyzed in order to understand the meaning of the phenomenon ${ }^{[19]}$, which is "student's learning towards becoming professional nurses, when supervised in pairs”.

The analysis process entails a movement between the whole, the parts and the whole. The aim is to search for and describe the essential meaning structures of the phenomenon.

After reading the transcribed interviews several times, the analysis started with a searching for meanings of the phenomenon where the text was divided into parts, termed "meaning units" ${ }^{[19,27]}$. Attempts to form clusters were made and the meaning units were grouped, based on similarities and differences of the meanings. In order to formulate the 
essence of the phenomenon we searched for patterns of meanings by seeking how the clusters were related to each other. Clusters, meanings and interviews were reread several times and the following questions were asked: "What implications do being supervised in pairs have for students' learning?”, "How is the student nurses' learning process towards their profession being promoted?” The essence emerged in the moving back and forth between the parts and the whole ${ }^{[19]}$.

\subsection{Ethical considerations}

The study passed the ethical self-review as proposed by the Ethical Advisory Board in Southeast Sweden ${ }^{[28]}$, and the Swedish Codes of Statutes (SFS) ${ }^{[29]}$ were taken into consideration. The study was also performed in accordance with the Declaration of Helsinki ${ }^{[30]}$. All of the participants were informed about the study both verbally and in writing. They also received information letters declaring all their rights and that this study would not affect their clinical studies and that the data would be saved for ten years. The participants signed consent to participate in the study and were ensured of confidentiality and that they would not be identified in the study. They were furthermore informed that if they were to decline to participate further at any time no further questions would be asked.

\section{Results}

The results are presented by a structure of meanings. Initially the more essential meanings are described and these are followed the phenomenon's constituents, which include the more contextual nuances of the phenomenon.

The essential meanings of the lived experiences of the learning process of nursing students towards their profession when supported by supervision in pairs are characterized by the space for learning, which is created both in terms of time and place and in the interaction with patients, supervisors and fellow students. Similarly the learning is restricted when the learning space is disturbed or reduced. Furthermore the phenomenon is characterized by a balanced responsibility, openness, flexibility in response between student and supervisor and a structured learning environment.

Responsibility is a focal point in learning in the progress towards becoming a professional nurse but has to be balanced in relation to the vulnerability that is generated by academic demands and performance assessment. The responsibility, which the student is expected to take immediately, and which initially can cause stress, worry and insecurity, gradually gives a sense of self-confidence and is seen as a breeding ground for learning. The great and immediate responsibility is on the one hand experienced as being frightening and on the other as something necessary in order to develop towards being independent. It is a challenge that students go through together in pairs and that unites them.

The phenomenon of being a pair of students entails being supportive of each other during their movement towards gaining independence and a comprehensive responsibility for the patient. Supervising each other and exchanging knowledge becomes a natural part of the joint learning process. A sense of being "us" that provides security and trust is created in the student pairs, and an implicit idea of fairness also emerges. The cooperation that takes place within each pair of students demands reciprocity where each student gives and takes and where their learning process can both develop and get space. Independence develops gradually and being a pair of students assumes a secondary role, but remains as a significant background for learning and support.

The focus of learning is on "doing" things such as healthcare technology and practical nursing tasks; with the consequence that the lifeworld of the patient is temporarily put in the background. Supervisors, who are successful in being present and confirmatory, but still not prominent, who wait and give time for reflection create a sense of security and an opportunity for the student to develop towards a professional nursing role. When supervisors take charge or do not succeed in giving responsibility, the students' learning is inhibited which generates stress, resignation and unobtrusiveness among the student nurses. The healthcare staff, routines and organizational structures as well as the supervisors are important for the progress or lack of progress of the students' learning process. This entails that the learning environment in its entirety has 
a potential for development, while at the same time being vulnerable and constantly changing where the seemingly unimportant is important for the students' learning.

Reflection is shown to be a focal point in the learning process and a natural part of the life of the student pair. It does not matter for the learning process if the reflection is planned or not. Reflection in a favorable atmosphere provides opportunities for the student nurses to reveal their weaknesses/their vulnerability and are supported and helped in moving on in the learning process. The reflection in the supervision "expands itself" and exists even outside the framework of the clinical placement, which means that reflection expands itself in both time and space.

The following constituents further elucidate the meaning of the phenomenon: The significance of responsibility for learning, The strength and sensitivity in pairs of students, The focus on doing, The significance of the attitude of the supervisor, The vulnerability and potential of the learning environment and Reflection as a possibility and a pre-requisite.

\subsection{The significance of responsibility for learning}

Responsibility is a central factor of importance for the students' learning process but also in their development towards independence and is described in a dialogue between a pair of students:

"The more responsibility you get the more you feel that you can take..."

"Yes...but also that you become a little more careful...because it's my patient ... and that includes you keeping an eye upon the patient more and learning more about the patient...”

The responsibility is described as "one develops... as a person...I'm able to do this" which is stimulating for their learning process. The responsibility is shown as being a balancing act between wanting it and not having the courage to take it. Being responsible can easily generate a feeling of being abandoned if they get too much responsibility on their own, which can lead to feelings such as stress, anxiety and insecurity. If students do not get the opportunity to take responsibility their learning process is inhibited and their self-esteem and their motivation to learn is affected and as a result students can become withdrawn, which is described as: "The less responsibility you get, the less you take...//...you get inhibited, you don't care that much.”

Responsibility leads them to look for security and support from those around them and the supervisor's evaluation can also make the students first look for support in their pairs "...stupid questions ....... I can discuss those with my student colleague before we go to our supervisor and then we can almost solve the problem together before seeing the supervisor." The students' learning process is dependent on how much responsibility the individual students get from their supervisor, and through their development they realize the gravity of having responsibility for a patient.

\subsection{The strength and sensitivity in pairs of students}

Being in pairs is important for students' learning where they can recognize themselves in each other, have security, interact and where reflection plays a major role. The students' teamwork is based on honesty and support for each other to solve problems that occur but also to learn from each other. In the initial phases of their clinical studies students tend to stay close in their pairs in order to develop towards being more independent. "It was really secure in the beginning being two", which enabled them to create a relationship with a feeling of trust that becomes important when supervising each other.

"To supervise a student...that feels natural to me...but if I was to be watched by a nurse...there'd immediately be a lot of pressure"...//... "If you ask me a question and I can't answer...then I can admit that."

Taking a step towards independence by caring for patients on their own but also returning to each other for support is based on the security provided in the student pair. Students describe independence as an important part of the caring and nursing 
of patients but that attention from the supervisor and support is important in order to take the step towards independency and for each to create their own way of caring. "When you are with someone you easily take after that person...but you have to find your own way... your own way of caring."

Even though being in pairs is supportive most of the time it also entails being vulnerable. Providing space for the other student in a pair may partly be at the expense of the one student's own learning. This could be the case when there is too little work to do at the clinical practice and they have to share it. To give and take is a necessity when cooperating in pairs, the learning process of both students has to develop and have space “...if you not are the sort of person who allows the other student to do things, if you only think of yourself, then of course there will be a rivalry and it's a pity for the other student...”

\subsection{The focus on doing}

The students' learning process tends to focus on performing healthcare technology, which then results in the patient perspective temporarily having to be in the background, the patient is not forgotten but is instead taken for granted. In order to learn healthcare technology students require space to focus on carrying out the practical work in order to facilitate learning about the complex nature of a patient's whole situation. There is a strong association between the profession and healthcare technology and thus the practice of healthcare technology skills is prioritized. "When it is about needles I get more nervous...then you have to prove yourself in some way.”

Even if they are focused on the "doing" they describe "how important and significant it is for the patients to give them time and to listen to what they have to say and pay attention to them as a person" in order to create an understanding for the whole patient. Students describe the importance of remembering that "there could be so much around a patient and to remember that there are so many dimensions to look at when you have time.” Even though healthcare technology is important for students they also describe that there is always a patient to care for, which is understood when caring with a lifeworld perspective and supported by supervision. "But when you meet a patient who is tired of life...which happened today...then I thought about the meaning of well-being and suffering.”

The students understand the importance of meeting a patient but need space and support in their learning in order to gain a greater understanding of what occurs in the interpersonal encounter. Supervision is needed in order to be able to gain an understanding of the complexity of a patient's whole situation in his/her context.

\subsection{The significance of the attitude of the supervisor}

Optimal supervision plays a great and definitive role in students' learning process and in supporting students in developing towards their professional role. Students feel secure "knowing that the supervisor is always nearby" when they know that their supervisor is able to support them. Supervision in the professional role provides students with the opportunity to understand the complexity of a patient situation and is also described as extending and broadening the care in order "to understand the whole patient." Supervisors who understand the students' perspective and inspire them to feel self-confident and give them support are important for the students' learning process. Supervisors who guide students with a reflective attitude are also described as being important, supervisors are an asset when they remain in the background or are as a stand-by who is familiar with the situation.

"I experience that as well so...she always has control all the time on what we are doing so that we don't forget anything...and then she lets us remember things on our own...think again now, have you done everything? And she is reflective...why is it like that? Why are you doing that? Letting us do it and keeping herself to one side, but always there in the background."

The students' learning process is interrupted when supervisors take control of the situation; it becomes the opposite of the help that is needed. At the same time as supervisors show deficiencies in their supervision, they are also unable to take a 
step back, thus obstructing the students' learning process, which is in contrast to supervisors who take a step back and are supportive for the students' learning process. There is a fine line between supportive and unsupportive supervision and a rhythm and flexibility is needed between students and supervisors in order for the supervision to be good. When the rhythm between students and supervisor is unbalanced students do not obtain space in learning, which is described as: "You learn when they don't interrupt and don't say things that you were just going to say yourself, but that you don't have time to because they are taking over the situation.”

\subsection{The vulnerability and potential of the learning environment}

Health care staff is important in the creation of a good learning environment for students, but when there is a lack of interest, support, understanding and response to the students the latter's learning and development is impeded and they withdraw when the environment is unfavorable for learning. "It is important with an environment where you can ask everyone....and that you are well received..." by health care professionals and that they are supportive in the students' learning process and understand their importance in the students' development. Not being accepted by health care professionals slows the learning process down and as a result students can be held back and “...it can be hard to delegate tasks to assistant nurses, especially if they are older and have been working here for a long time or so...they might feel that here comes a student who thinks that she knows everything and is going to give me tasks to do...”

Supportive healthcare professionals create a good learning environment, which demonstrates the possibilities that teamwork can give and which also clarifies the use of theory in practice. Supportive supervisors who reduce stress and chaos by giving continuous feedback are of importance for the development of students towards being a professional nurse, which is described as: "To get feedback on how you are getting on...I felt stronger after that...after that I was more independent and I felt, yes I can do this and that's very important.”

The students' learning process benefits from not being supervised when they feel secure in performing healthcare technology, as being exposed to the supervisor can create an inner stress to succeed and an obstacle in learning to be independent due to the feeling of being assessed. To be watched by a supervisor and fail is difficult, on the other hand if the supervisor takes a step back and keeps a low profile, then he/she is supportive.

"I feel the same (within a student pair), that you are calmer than when a nurse is to stand and watch you...I don't know why I'm like that...but, it is probably as I said, that you are on the same level...and that you know a little more what you are uncertain about maybe...you understand it in another way..."

\subsection{Reflection as a possibility and a pre-requisite}

Reflection is an opportunity and a pre-requisite for students to develop in their learning process. Reflection is supportive for students' learning both when planned with the supervisor and other students or when occurring spontaneously. The students' learning process benefits when they get the space needed for reflection, whether it is planned or not the learning process is expanded and creates security for the learning.

"We have reflected on what has happened during the day and what we have done and what we have forgotten and so on...partly what we have learned and how to do it in another way...yes, you develop all the time...in these times for reflection."

Being in student pairs is important when finding time for reflection; they have moments of reflection during the whole day, sometimes "when we are on our way home... asking how it's been and if something special has happened" which can develop the reflection and learning process outside the clinical placement. Self-reflection is also an important way for students to process the caring situations as well as getting them to reflect about the caring situations and to develop in their professional role. The clinical practice is important when integrating theoretical knowledge and practice "if you first read the theory and then see it in reality then you can see that the two are linked together" but at the same time students become 
aware of their lack of knowledge when they are reflective “... felt that there's quite a lot of medical knowledge that I lacked, which I would have to study more.”

Learning in integrating theory and practice is often superficial but not always reflective; a learning process that stimulates the students' reflection and potential is needed in professional supervision. The inclusion of the science of caring in reflection is necessary for the learning process of professional caring but also for the understanding of the lifeworld of the patient.

"In the first part of the education you were thinking what's this, it feels fairly unnecessary, I really think it is, but now when I am almost done I think it's good that I've learned...perhaps a bit much, it feels like I've been talking about these concepts endlessly (caring science concepts), no but...but it's really as I say, I've learnt them by heart."

\section{Discussion}

Responsibility is a prominent feature of the result in this study; it appears to be difficult both for pair of students and supervisors to find the right balance of responsibility. Responsibility entails caring for patients and how this could lead to

them experiencing well-being ${ }^{[31-33]}$. Responsibility also entails a question of creating a balance and it is difficult for students to balance between their responsibilities and the ever present vulnerability. If they are successful in managing this challenge then they can develop further as human beings. Students appear to lose a sense of responsibility if they do not receive enough of it and appear to be overwhelmed if they receive too much of it, and their experience is that it all depends on how much responsibility their supervisors are willing to give them.

The results show that responsibility is often founded upon the security that the supervisor feels. In the same way that the pair of students needs security in order to facilitate their learning process, the supervisors need security in order to facilitate a good attitude in their role as supervisors. Berglund et al. ${ }^{[5]}$ also describe the importance of both students and supervisors receiving support for facilitating students' learning and their ability to intertwine theory and praxis.

Hörberg, Ozolins and Ekebergh ${ }^{[34]}$ maintain that it is important to develop conditions where the students' lifeworld is the foundation in the learning process. The students' different fields of knowledge; caring science, practical skills and the lifeworld, which constitute the subjective and the lived knowledge, are important to interweave and integrate through reflection and are crucial for the creation of a whole. The lifeworld perspective is important when students learn, both individually and in pairs, but also when students care for their patients. Each student has to develop individually and gain support individually even though they are supervised in pairs. Learning and life cannot be separated; caring and education are thus intertwined with caring sciences and life ${ }^{[34]}$. Students' learning is of the environment they are in, which includes both learning support and the learning environment they are placed in, which also means that students are of each other in "pairs of students" and of each other's learning. Students are closely linked with their learning environment; the body, soul and world cannot be separated and according to Merleau-Ponty ${ }^{[23]}$ who illustrates "the flesh of the world", students cannot be separated from their learning environment. The opportunity for patients to be cared for in a safe environment with good caregivers is also "of" the students' possibility for receiving support in their learning process of caring in pairs. If students can receive good examples of good care it is easier for them to provide good care as well, students are thus "of" the environment in which they are placed.

The learning space that is created in the encounters between student-patient, student-student and student-supervisor has also been seen to be an important finding. This learning space can be seen as an interspace where the students' learning and development towards their profession starts, the space constitutes a foundation for reflection and for development towards a greater understanding of caring science and praxis. This learning space has a special significance for learning in pairs and can be further understood with the help of Dahlberg ${ }^{[35]}$, who has analyzed the meaning of 'flesh' in Merleau-Ponty ${ }^{[23]}$ as 
constituting the meeting between two bodies, where something more is created in the space between these two bodies, and where they confirm each other as being separated and interrelated at the same time. There is an interrelated understanding between two bodies that creates one body from the two in that in-between meeting. In order to gain support in the learning environment and in the encounters in the interspace, pair of students have to have space and time in order to discuss the care that they are providing when learning. This is important when meeting patients, student colleagues and supervisors. There is a fine line between supportive and unsupportive supervision, where the latter entails that students need to have space for their learning. The learning process also has to retain a rhythm and flexibility between each student within pairs and supervisor, in order to obtain the necessary space and time for learning both individually and in pairs. Without this space and time the learning can be obscured, and thus the supervisors have to wait for each student to learn and to develop at their own pace. Ozolins ${ }^{[36]}$ maintains that the inter-subjective relationship is of importance because all inter-subjective meetings have a meaning, a meaning that is unique for every person, which defines their own health and suffering. This could be understood as meaning that all meetings can generate development between a student and a supervisor, a student and a student, and a student and a patient. In the same way that the lifeworld of a patient can be obscured the lifeworld of a student can be obscured and thus also their learning process.

Students also experience that they feel safe in pairs; they explain the feeling as being in the same "boat". Galvin and Todres ${ }^{[37]}$ explain this experience of belongingness as being "mutually complementary". Being together and helping each other in pairs also provides the students with the strength to become independent, which according to Galvin and Todres ${ }^{[37]}$ could be seen as a "more” when pairs of students can work together. Being as they are different persons they each bring something new to the relationship, in which students can help each other to see new aspects of caring for patients. Galvin and Todres ${ }^{[37]}$ also explain the feeling of being "at home" and the feeling of having an "adventure" which could be found in pairs of students, which can generate both a sense of safety and tension in pairs of students that could help them to develop further. Galvin and Todres ${ }^{[37]}$ explain further that there is an inter-subjective relationship between two people that has a mutual sense of safety, which also gives them different experiences that they can learn from. This can be understood as there being two different persons, who have two different lifeworlds, in a pair of students and they thus experience things in the same way but also in different ways, which can bring different dimensions to their cooperation. This could be the case when a pair of students has time for reflection.

The results indicate that it is particularly important for the students to work in pairs in the early stages of their clinical studies. Findings from earlier studies showed that most students feel anxiety in the beginning of the clinical studies ${ }^{[8]}$, which thus can strengthen the ties between the students, who find themselves in the same situation and are willing to help each other. Working in pairs can also be seen to be one of the strong features of this supervision model; students learn to cooperate, share their feelings, help each other and furthermore become stronger together, which facilitates a learning situation and the potential for growth towards becoming professional nurses.

Another aspect, which is also seen to be favorable for students' learning in pairs, is that they become directly involved in the care of the patients, and consequently manage to be independent in pairs. Holst and Hörberg ${ }^{[18]}$, Benner et al. ${ }^{[1]}$ and Levett-Jones et al. ${ }^{[7]}$ declare that students, who get involved in the caring, also feel important and become motivated to do well. However in order to learn from each other and to share experiences students need time for reflection and they need different kinds of reflection. They need, as described in the results of the present study, to reflect in their pairs but also to have structured reflection to deepen their theoretical knowledge for use in the practical field. Students require reflection both in pairs and independently before and after meeting with patients, and this becomes more evident when they are exposed to real feelings. In conclusion the students need to reflect in order to bridge the gap between theory and practice. Students can sometimes focus on healthcare technology and at one point in time take the patient for granted. In these situations it is important for students to reflect upon the meanings of caring science in relation to the encounter with the patient in order that the patient perspective is not forgotten. This could with favorable take place within pairs were students develop their reflective attitudes as explained earlier with different aspects of situations and the feeling of "at home" and in "adventure". 


\subsection{I mplications for clinical practice in nursing education}

Result in this study could be supportive for nursing educators in developing clinical practice. Supervision in pairs seems to be important for students learning, whether in pairs or not, supervision requires support to strengthen students' independence and development towards becoming a nurse. Following statements could be helpful in introducing supervision in pairs of students in clinical practice:

The responsibility that students receive during their clinical studies must be handled with caution in the inter-subjective relationship between students and their supervisor.

The supervising approach and ability to meet students' lifeworld is crucial to create a successful support of students learning process.

When pairs of students are cooperating well it gives them a big boost in learning, they dare to challenge themselves because of their feelings of belonging and security.

The learning space that is created in the encounter between student-patient, student-student and student-supervisor is important being as it constitutes the starting point of a reflection, which contributes to the development towards their professional role.

\subsection{Methodological considerations}

This study was conducted at Developing and Learning Care Unites. On one hand it could be understood as an advantage that the study is conducted within this specific context, as the main results could appear more obviously. On the other hand structures within this didactic model could affect the results of this study and possibly limit the transferability to general clinical practice. However, one can argue that transferability is possible when the level of analysis shows, as in our case, both the phenomenon's general level as well as a more contextual level.

Data was collected in the end of five week practice; this to get a rich description of the students experiences of being supervised in pairs but also to increase their possibilities to share experiences of their learning in clinical practice, i.e. both advantages and disadvantages. The students who agreed to participate in the study had experienced that they had cooperated well in their pairs and those who had not cooperated well may perhaps have declined to participate in the study. Pairs of students, where only one student agreed to participate, were not interviewed because the aim was to capture the experiences of both student nurses in a pair, and the inter-subjective meeting between students in the interview situation. The results would probably have been more diverse if pairs of students who had not cooperated well had been included in the study. In order to include pairs of students who had not cooperated well in future studies the sampling procedure would have to be performed in a different way.

Both authors were involved in the analyzing process in order to strengthen the validity but also to secure that nothing was ascribed to the phenomenon that did not belong to it. The bridling of the authors' pre-understanding was in focus throughout the analyzing process and the authors' understanding was thoroughly discussed during the whole process.

\section{Conclusion}

The study shows that the conduct of supervising in pair of students is of great importance for students' learning and it is thus important to develop a reflective supervising approach and also knowledge of how to support students' learning.

Didactics with a lifeworld perspective could be helpful for supervisors in order to facilitate and support a learning approach for student's lifeworld, this to develop supervisors understanding as much as possible of how students perceive 
their situation. In order to create an understanding of the patient in his/her context, the situation has to be clarified through support and supervision where theory enriches the practice and vice versa.

In order to gain a greater understanding of students' learning processes in pairs during their clinical studies further research is needed. Studies from the supervisor's perspective are important in order to illustrate how they can support students in their learning situation and in order to gain a greater understanding of how the conduct of the supervising process could be developed. Furthermore it would be interesting to compare students supervised in pairs in this structure with students receiving individual supervision.

\section{Conflicting interest}

There are no interests of conflict to declare.

\section{References}

[1] Benner P, Sutphen M, Leonard V, Day L. Educating nurses: a call for radical transformation. San Francisco: Jossey-Bass. 2011: 19-200.

[2] Ekebergh M. A learning model for students during clinical studies. Nurse Education in Practice. 2011; 11: 384-389. PMid:21489878 http://dx.doi.org/10.1016/j.nepr.2011.03.018

[3] Ekebergh M. Developing a didactic method that emphasizes lifeworld as a basis for learning. Reflective Practice. 2009a; 10(1): 51-63. http://dx.doi.org/10.1080/14623940802652789

[4] Ekeberg M. Att lära sig vårda, med stöd av handledning. [The learning about caring with support in supervision]. Lund: Studentlitteratur AB. 2009b: 15-213.

[5] Berglund M, Sjögren R, Ekebergh, M. Reflect and learn together - when two supervisors interact in the learning support process of nurse education. Journal of Nursing Management. 2012. http://dx.doi.org/10.1111/j.1365-2834.2011.01368.x

[6] Holmsen L. Hva påvirker sykepleierstudentenes trygghet og laering i klinisk praksis? Vård i Norden. 2010; 30(1): $24-28$.

[7] Levett-Jones T, Lathlean J, Higgins I, McMillan M. Staff-student relationship and their impact on nursing students' belongingness and learning. Journal of Advanced Nursing. 2009; 65(2):316-324. PMid:19191935 http://dx.doi.org/10.1111/j.1365-2648.2008.04865.x

[8] Sharif F, Masoumi S. A qualitative study of nursing student experience of clinical practice. BMC Nursing. 2005 ; 4(6): 1-7.

[9] Severinsson E. Bridging the gap between theory and practice: a supervision programme for nursing students. Journal of Advanced Nursing. 1998; 27: 1269-1277. PMid:9663879 http://dx.doi.org/10.1046/j.1365-2648.1998.00644.x

[10] Jokelainen M, Turunen H, Tossavainen K, Jamookeeah D, Coco K. A systematic review of mentoring nursing students in clinical placements. Journal of Clinical Nursing. 2011; 20: 2854-2867. PMid:21429055

http://dx.doi.org/10.1111/j.1365-2702.2010.03571.x

[11] Landers MG. The theory-practice gap in nursing: the role of the nurse teacher. Journal of Advanced Nursing. 2000; 32(6): 1550-1556. PMid:11136425 http://dx.doi.org/10.1046/j.1365-2648.2000.01605.x

[12] Löfmark A, Wikblad K. Facilitating and obstructing factors for development of learning in clinical practice: a student perspective. Journal of Advanced Nursing. 2000; 34(1): 43-50. http://dx.doi.org/10.1046/j.1365-2648.2001.3411739.x

[13] Paercey P A, Elliott B. Student impressions of clinical nursing. Nurse Education Today. 2004; 24: 382-387. PMid:15245861 http://dx.doi.org/10.1016/j.nedt.2004.03.007

[14] Severinsson E, Sand Å. Evaluation of the clinical supervision and professional development of student nurses. Journal of Nursing Management. 2010; 18:.669-677. PMid:20840361 http://dx.doi.org/10.1111/j.1365-2834.2010.01146.x

[15] Slaughter-Smith C, Helmes JE, Burris R. Nursing Staff Perceptions of Students Contributions in Clinical Settings. Journal of Nursing Education. 2011; 51(1): 54-57. PMid:22132717 http://dx.doi.org/10.3928/01484834-20111130-02

[16] Ekebergh M. Lifeworld-based reflection and learning: a contribution to the reflective practice in nursing and nursing education. Reflective Practice. 2007; 8(3): 331-343. http://dx.doi.org/10.1080/14623940701424835

[17] Ekebergh M, Lepp M, Dahlberg K. Reflective learning with Drama in Nursing Education - a Swedish attempt to overcome the theory praxis gap. Nurse Education Today. 2004; 24: 622-628. PMid:15519445 http://dx.doi.org/10.1016/j.nedt.2004.07.011

[18] Holst H, Hörberg U. Students’ learning in an encounter with patients - supervised in pair of students. Reflective Practice. 2012; 13(5): 693-708. http://dx.doi.org/10.1080/14623943.2012.670623

[19] Dahlberg K, Dahlberg H, Nyström M. Reflective Lifeworld Research. Stockholm: Studentlitteratur. 2008: 29-350. 
[20] Husserl E. The crisis of European sciences and transcendental phenomenology. (D. Carr, Trans.). Evanston, IL: Northwestern University Press. 1970/1936: 3-265.

[21] Husserl E. Cartesian meditations: an introduction to phenomenology. (D. Cairns, Trans.). The Hague: Martinus Nijhoff. 1977/1929: 27-157. http://dx.doi.org/10.1007/978-94-009-9997-8

[22] Merleau-Ponty M. Phenomenology of perception. (C. Smith, Trans.). London: Routledge. 2002/1945: 77-530.

[23] Merleau-Ponty M. The visible and the invisible. (A. Lingis, Trans.). Evanston, IL: Northwestern University Press. 1968/1964: 3-162.

[24] Dahlberg H, Dahlberg K. To Not Make Definite What is Indefinite: A Phenomenological Analysis of Perception and its Epistemological Consequences in Human Science Research. Journal of the Humanistic Psychologist. 2003; 31(4): 34-50. http://dx.doi.org/10.1080/08873267.2003.9986933

[25] Dahlberg K. The individual in the world-the world in the individual: towards a human science phenomenology that includes the social world. Indo-Pacific Journal of Phenomenology. 2006; 6 Special edition: 1-9.

[26] Ekebergh M. Livsvärldsdidaktik på vårdvetenskaplig grund i sjuksköterske- och specialistutbildningar: Utveckling av en handledningsmodell. [Lifeworld didactic with caring science in nursing- and specialist educations: Development of a supervision model]. Göteborg: Intellecta Infolog. 2009c: 10-113. Available from: http://lnu.diva-portal.org/smash/record.jsf?searchId=2\&pid=diva2:291723 (9 March 2012, date last accessed).

[27] Giorgi A. The descriptive phenomenological method in psychology: a modified husserlian approach. Pittsburgh: Duquesne Univ Press. 2009: 87-128.

[28] Ethical Advisory Board in Southeast Sweden. 2011. Available from: http://www.bth.se/eksydost (9 March 2012, date last accessed).

[29] Swedish Codes of Statutes (SFS) (2003:460), (1998:204) and (1980:100), 2011. Available from: http://www.riksdagen.se/webbnav/index.aspx?nid=3912 (9 March 2012, date last accessed).

[30] World Medical Association Declaration of Helsinki, 2008. Available from: http://www.wma.net/en/30publications/10policies/b3/ (9 March 2012, date last accessed).

[31] Dahlberg K. Lifeworld Phenomenology for Caring and for Health Care Research. In Qualitative Research in Midwifery and Childbirth: Phenomenological Approaches. G. Thomson, F. Dykes, S. Downe, ed. London: Routledge. 2011: 17-34.

[32] Dahlberg K, Segesten K. Hälsa och vårdande i teori och praxis. [Health and caring in theory and practice]. Stockholm: Natur \& Kultur. 2010: 13-255.

[33] Dahlberg K, Todres L, Galvin K. Lifeworld-led health care is more than patient-led care: an existential way of well-being. Medicine Health Care and Philosophy. 2009; 12: 265-271. PMid:19101822 http://dx.doi.org/10.1007/s11019-008-9174-7

[34] Hörberg U, Ozolins L-L, Ekebergh M. Intertwining caring science, caring practice and caring education from a lifeworld perspective - two contextual examples. International Journal of Qualitative studies on Health and Well-being. 2011 ; 6 : 10363 http://dx.doi.org/10.3402/qhw.v6i4.10363

[35] Dahlberg H. Vikten av kropp. Frågan om kött och människa i Maurice Merleau-Pontys Le visible et l'invisible. [The Weight of the Body. The Question of Flesh and Human Being in Maurice Merleau-Ponty's Le visible et l'invisible]. (In Swedish, PhD thesis). Gothenburg University, Sweden. 2011: 363-368.

[36] Ozolins L-L. Beröringens fenomenologi i vårdsammanhang. [The phenomenology of touch in healthcare]. (In Swedish, PhD thesis). Växjö: School of Health and Caring Sciences, Linnaeus University, Sweden. 2011: 189-201. Available from: http://lnu.diva-portal.org/smash/record.jsf?pid=diva2:434424\&searchId=1 (9 March 2012, date last accessed).

[37] Galvin G, Todres L. Kinds of well-being: A conceptual framework that provides direction for caring. International Journal of Qualitative Studies on Health and Well-being. 2011; 6: 10362. http://dx.doi.org/10.3402/qhw.v6i4.10362 